\title{
Complexities in Integrating Social Risk Assessment into Health Care Delivery
}

\author{
Nibarika Khanna, MD, MBBS, DGO
}

( J Am Board Fam Med 2020;33:179-181.)

Keywords: Delivery of Health Care, Health Equity, Patient Care Team, Patient Preference, Population Health, Risk Factors, Social Determinants of Health, Social Work

The health care sector is mobilizing to identify and intervene on social risks that impact health. ${ }^{1}$ Social risk screening under the Centers for Medicare and Medicaid Innovation Accountable Health Communities demonstration project has led to multiple observations of high acceptability of social risk screening in primary care and emergency department patients. ${ }^{2}$ Patients report insights into the recognition of social risks impacting their own health and reflect on the limitations of the health care sector in addressing social adversity. ${ }^{3}$ However, there is a lack of clarity on who should be screened and when, who should do the screening, and how this new procedure should be implemented in the health sector. A United States Preventive Services Task Force workgroup is developing a road map toward prioritizing social determinants of health as a clinical preventive service. ${ }^{4}$ In addition, there are lessons to be learned from using Social Deprivation or Area Deprivation Indices to develop payment programs that can institutionalize social risk screening and linkages to necessary social supports in the health care sector. ${ }^{5}$

Neighborhood socioeconomic disadvantage is a predictor of health access, health indices, health

From the Department of Family and Community Medicine, University of Maryland School of Medicine, Baltimore (NK).

Funding: None, except through departmental supports.

Conflicts of Interest: None.

Corresponding author: Niharika Khanna, MD, MBBS, DGO, Professor Family and Community Medicine, University of Maryland School of Medicine, 29 South Paca Street, Baltimore, MD 21201 (E-mail: NKhanna@som. umaryland.edu).

\section{See Related Article on Page 170.}

care burdens, and health care costs and limits the ability of the health care system to impact disease. There are a number of ways that socioeconomic disadvantage can impact health, including the following 4 broad time points in a person's life: at birth, predisease, during disease, and at the end of life. Socioeconomic disadvantage determines the geographic area that patients may live in, whereas Area Deprivation Indices may describe factors that impact health and disease. ${ }^{6,7}$ Furthermore, low socioeconomic status may determine prematurity, childhood malnourishment and neglect, and risk behaviors such as tobacco use and lack of exercise, which contribute to poor outcomes. The geographic distribution of fresh food markets, area exercise facilities, education, crime, poverty, and the availability of shelter are also factors that determine the health of the population located in the region and particularly impact Ambulatory Care Sensitive Conditions and the burden of disease measured as Hierarchical Condition Category. ${ }^{8-10}$ Prior studies have documented the relationship of Area Deprivation Index with mortality, hospital readmission, and related health outcomes. ${ }^{11-13}$ The Area Deprivation Index has multiple definitions, and 1 such definition has utilized 17 variables to identify the characteristics that impact health. ${ }^{6} \mathrm{It}$ is evident that neighborhood predictors of health are a complex group of variables, with possible complex solutions that do not exist in the health care system at present. It is also important to recognize the role that rurality and entrenched race/ ethnicity-linked disadvantages may play in disease and in life expectancy. ${ }^{14}$

Health care stakeholders, including payers, purchasers, providers, and patients, are working on a 
clear and consistent taxonomy for social determinants of health, to distinguish social determinants of health, social risks, and social needs and to identify factors impactable by payers and providers. ${ }^{15} \mathrm{~A}$ recent consensus building exercise by the National Academies of Sciences, Engineering and Medicine (NASEM) has laid out a path toward a better understanding of the integration of social risk into health care. ${ }^{16,17}$ NASEM reports suggest that social care resources can be integrated into health care with appropriately trained social care workforce, health information technology innovations, and new financing models. This systematic strategy has a greater likelihood of success in an iterative process with the identification of key players at each step.

In this issue, De Marchis et al. ${ }^{18}$ query "do patients want help addressing social risks"? This is an interesting view of social determinants of health from the perspective of patients and practices. In most multifaceted concepts, diverse perspectives can be compiled to present the whole. From the patients' perspective, the ability of a primary care practice to impact the particular social determinant may seem possible or sometimes impossible and hopeless. Practices located in geographic regions with high Area Deprivation Indices may consider it important to screen for social determinants of health to link patients to community resources and to set achievable goals with patients. ${ }^{19}$ Conversely, an individual living in a geographic region with high Area Deprivation Indices may be relatively less likely to think that simple interventions at the physicians' office will impact the social determinants specific to their situation. ${ }^{13}$ Historically, physician offices have been the sites for health care delivery and not for solutions to socioeconomic disadvantage and low neighborhood resources. Furthermore, electronic health records are not configured to systematically collect social risk data. ${ }^{20}$ De Marchis et al. ${ }^{18}$ present a relevant perspective to inform the scientific discussion on social risks.

The ability of primary care to impact disease is modulated by social factors or social determinants of health. ${ }^{21}$ Thus, understanding a patient's limitations in self-management including extrinsic and neighborhood factors is important for the delivery of care and goal setting for the patient. Screening using an accurate tool can yield results that identify pertinent social factors, and zip code data can provide information on neighborhood Area Deprivation Indices. These 2 sets of observations can be a way to place social factors in contextual relevance to their disease and to expected outcomes. Managed care organizations may also be 1 place to test social risk concepts relevant to health. 22

A great deal of work is needed by physicians, social workers, policymakers. and other stakeholders to identify a precise pathway to integrating social care into health care delivery. The NASEM consensus report forms the foundation on which to lay the innovations in social workforce retraining and integration into primary care, health information technology innovations, and payment methodologies necessary for a primary care practice to act on social factors that impact health care delivery and health related outcomes.

To see this article online, please go to: http://jabfm.org/content/ 33/2/179.full.

\section{References}

1. Gottlieb LM, DeSalvo K, Adler NE. Healthcare sector activities to identify and intervene on social risk: an introduction to the American Journal of Preventive Medicine supplement. Am J Prev Med 2019;57:S1-S5.

2. De Marchis EH, Hessler D, Fichtenberg C, et al. Part I: a quantitative study of social risk screening acceptability in patients and caregivers. Am J Prev Med 2019;57:S25-S37.

3. Byhoff E, De Marchis EH, Hessler D, et al. Part II: a qualitative study of social risk screening acceptability in patients and caregivers. Am J Prev Med 2019;57:S38-S46.

4. Krist AH, Davidson KW, Ngo-Metzger Q, Mills J. Social determinants as a preventive service: U.S. Preventive Services Task Force methods considerations for research. Am J Prev Med 2019;57:S6-S12.

5. Huffstetler AN, Phillips RL. Payment structures that support social care integration with clinical care: social deprivation indices and novel payment models. Am J Prev Med 2019;57:S82-S88.

6. Singh GK. Area deprivation and widening inequalities in US mortality, 1969-1998. Am J Public Health 2003;93:1137-43.

7. Sapra KJ, Yang W, Walczak NB, Cha SS. Identifying High-Cost Medicare Beneficiaries: Impact of Neighborhood Socioeconomic Disadvantage. Popul Health Manag. In press.

8. Butler SM. Building blocks for addressing social determinants of health. JAMA 2017;318:1855-6.

9. Finegan MS1, Gao J, Pasquale D, Campbell J. Trends and geographic variation of potentially avoidable hospitalizations in the veterans health-care system. Health Serv Manage Res 2010;23:66-75. 
10. Dimitrovová K, Costa C, Santana P, Perelman J. Evolution and financial cost of socioeconomic inequalities in ambulatory care sensitive conditions: an ecological study for Portugal, 2000-2014. Int J Equity Health 2017;16:145.

11. Kind AJ, Jencks S, Brock J, et al. Neighborhood socioeconomic disadvantage and 30 day rehospitalizations: an analysis of Medicare data. Ann Intern Med 2014;161:765-74.

12. Knighton AJ, Savitz L, Belnap T, Stephenson B, VanDerslice J. Introduction of an Area Deprivation Index measuring patient socioeconomic status in an integrated health system: implications for population health. EGEMS 2016;4:1238.

13. Kind AJH, Buckingham WR. Making neighborhood disadvantage metrics accessible-the Neighborhood Atlas. N Engl J Med 2018;378:2456-8.

14. Henning-Smith CE, Hernandez AM, Hardeman RR, Ramirez MR, Kozhimannil KB. Rural counties with majority black or indigenous populations suffer the highest rates of premature death in the US. Health Aff (Millwood) 2019;38:2019-26.

15. Green K, Zook M. When talking about social determinants, precision matters. Health Affairs Blog. https://www.healthaffairs.org/do/10.1377/ hblog20191025.776011/full/. Published October 29, 2019.
16. Bibbins-Domingo $\mathrm{K}$. Integrating social care into the delivery of health care. JAMA 2019;322: 1763-4.

17. National Academies of Sciences, Engineering, and Medicine. Integrating social care into the delivery of health care: moving upstream to improve the nation's health. Washington, DC: National Academies Press; 2019.

18. De Marchis EH, Alderwick H, Gottlieb LM. Do patients want help addressing social risks? J Am Board Fam Med. In press.

19. Davidson KW, McGinn T. Screening for social determinants of health: the known and unknown. JAMA 2019;322:1037-8.

20. Cottrell EK, Dambrun K, Cowburn S, et al. Variation in electronic health record documentation of social determinants of health across a national network of community health centers. Am J Prev Med 2019;57:S65-S73.

21. George A, Sachdev N, Hoff J, et al. Development, value, and implications of a comprehensive primary care payment calculator for family medicine: report from Family Medicine for America's Health Payment Tactic Team. Fam Med 2019;51:185-92.

22. Butler SM. How an expanded vision of managed care organizations could tackle inequities. JAMA 2019;321:2063-4. 